\title{
Appendiceal mucocele in ulcerative colitis
}

A 55-year-old woman with ulcerative colitis underwent colonoscopy with a view to assess the activity and extent of disease. During the procedure, a $2.5-\mathrm{cm}$, smooth, rounded lesion ( $\mathbf{F i g . 1}$ ) was found in the cecum, distal and separate from the ileocecal valve; the overlying mucosa had a normal appearance.

A contrast computed tomography (CT) scan of the abdomen showed that the appendix was dilated with low-attenuation fluid to $1.5 \mathrm{~cm}$ ( Fig. 2; arrow) and showed calcification at its origin and tip. Based on these findings a diagnosis of mucocele of the appendix was suspected. The patient was referred for laparoscopic resection and a right-sided hemicolectomy was carried out. The surgical specimen included a dilated appendix, $2.8 \mathrm{~cm}$ in diameter ( $\bullet$ Fig. 3; arrow); sectioning revealed a $1.3-\mathrm{cm}$ spherical tumour.

Histological examination showed this to be a mucinous cyst adenoma with low grade dysplasia ( $\bullet$ Fig. 4 ).

Mucoceles of the appendix are uncommon lesions caused by distension of the appendix with mucinous material. There are four main types: simple or retention mucoceles, hyperplastic mucoceles, mucinous cyst adenomas, and mucinous cystadenocarcinomas [1]. Mucoceles of the appendix can be asymptomatic or present with abdominal pain or bleeding, or as a palpable abdominal mass. Rarely they cause intestinal obstruction, intussusception, ureteric obstruction, volvulus, or cutaneous fistulae [2]. The most feared complication is pseudomyxoma peritonei, because of spontaneous or iatrogenic rupture that results in seeding of neoplastic cells in the peritoneal cavity. Colonoscopy, $\mathrm{CT}$, and ultrasound can all help in diagnosis [3]. As it is difficult to differentiate between benign and malignant lesions causing mucocele, resection is recommended. There have been case reports of appendiceal mucocele in patients with ulcerative colitis. It has been suggested that appendicular involvement with inflammation, or an associated appendicular neoplasm, in such patients leads to blockage and formation of a mucocele [4].

Endoscopy_UCTN_Code_CCL_1AD_2AD

Endoscopy_UCTN_Code_CCL_1AD_2AJ

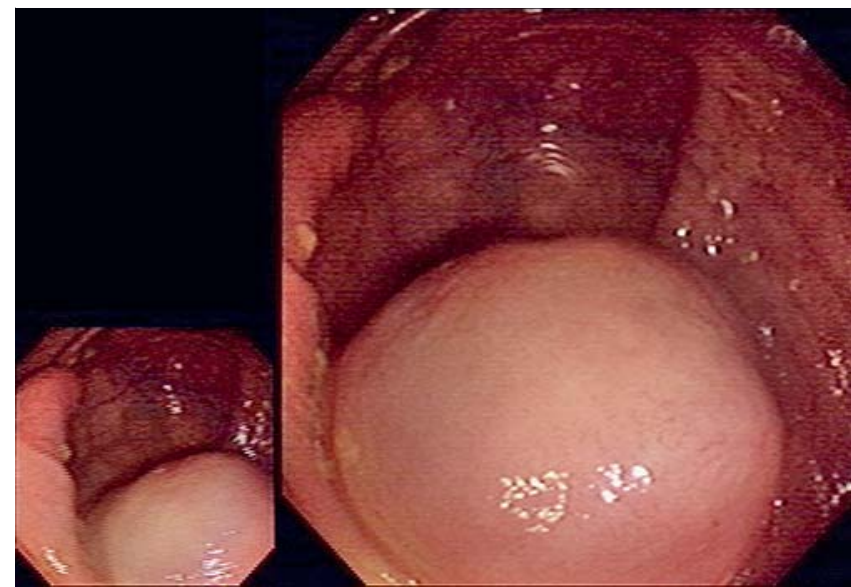

Fig. 1 Colonoscopic view of the lesion.

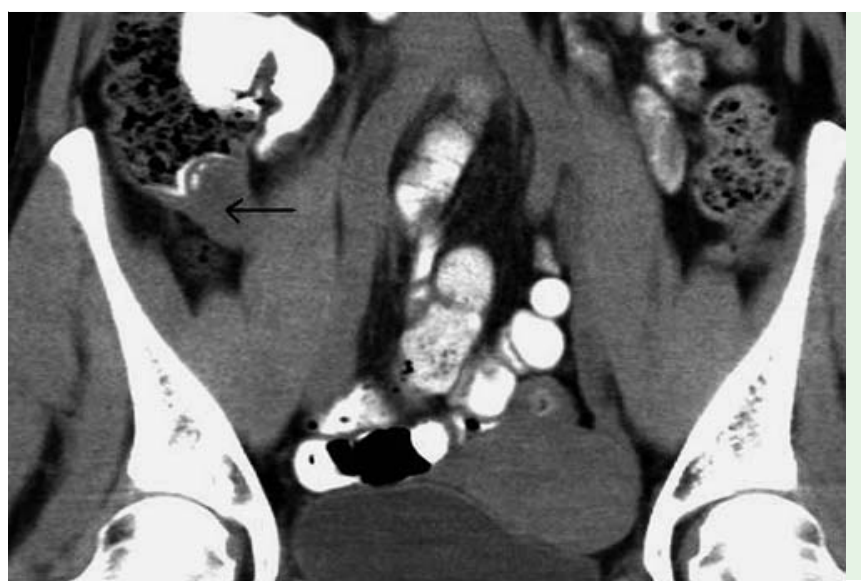

Fig. 2 Computed tomography (CT) scan of the lesion showing a fluid-filled, dilated appendix (arrow).

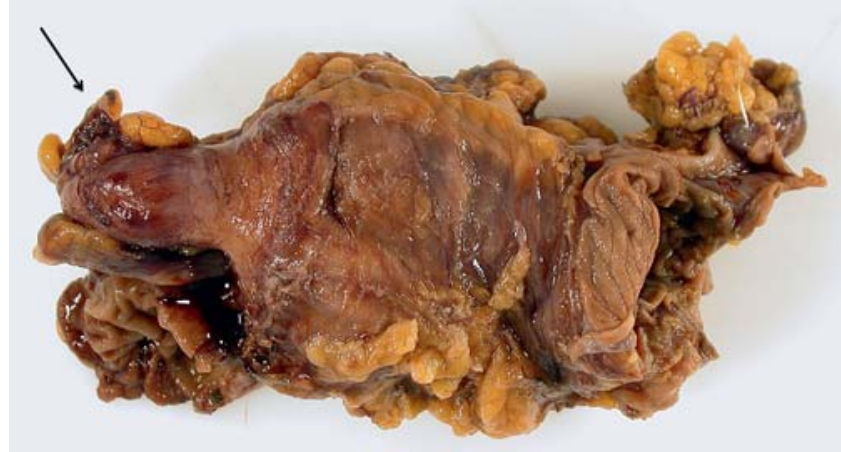

Fig. 3 Resected specimen with appendix (arrow).
T. Ghosh, A. Chalmers, C. Verbeke,

R. Saunders, S. M. Everett

Leeds General Infirmary, Great George

Street, Leeds, UK

\section{References}

1 Rampone B, Roviello F, Marrelli D, Pinto E. Giant appendiceal mucocele: report of a case and brief review. World J Gastroenterol 2005; 11 (Suppl 30): 4761-4763
2 Karakaya K, Barut F, Emre AU et al. Appendiceal mucocele: case reports and review of current literature. World J Gastroenterol 2008; 14 (Suppl 14): 2280-2283

3 Madwed D, Mindelzun R, Jeffrey RB Jr. Mucocele of the appendix: imaging findings. AJR Am J Roentgenol 1992; 159 (Suppl 1): 69-72

4 Lakatos PL, Gyori G, Halasz J et al. Mucocele of the appendix: an unusual cause of lower abdominal pain in a patient with ulcerative colitis. A case report and review of literature. World J Gastroenterol 2005; 11 (Suppl 3): $457-459$ 


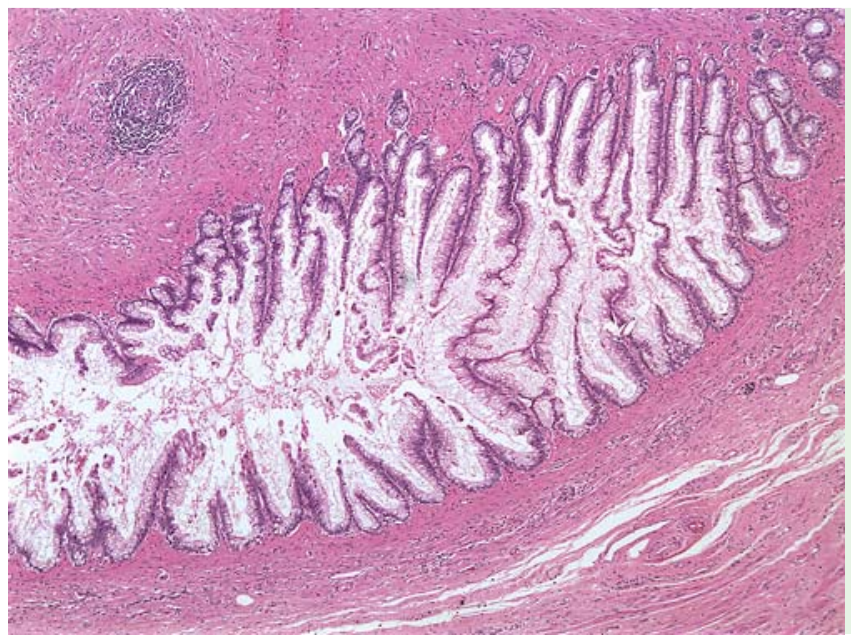

Fig. 4 Histological section of the resected tumour.

\section{Bibliography}

DOI $10.1055 / \mathrm{s}-0029-1243913$

Endoscopy 2010; 42: E105 - E106

(c) Georg Thieme Verlag KG Stuttgart · New York . ISSN 0013-726X

Corresponding author T. Ghosh, MBBS, MRCP

Leeds General Infirmary Great George Street Leeds LS1 3EX UK

ghosh_tilak@yahoo.com 